\title{
Study of the bio-insecticidal power of Pistacia lentiscus and Pisatcia atlantica from Tlemcen region
}

\author{
Bereksi Reguig $\mathbf{M}^{1 *}$, Abdelli $\mathrm{I}^{2,3}$, Hassani $\mathrm{F}^{1}$, Bekkal Brikci $\mathrm{S}^{1}$ \\ 1 Faculté SNV.STU-Université de Tlemcen 13000-Laboratoire d'Ecologie \& Gestion des \\ Ecosystèmes Naturels Tlemcen Algérie. \\ 2 Ecole Supérieure en Sciences Appliquées Tlemcen Algérie \\ 3 Laboratoire des Substances Naturelles et Bioactives (LASNABIO)- Faculté des Sciences-Université - \\ Tlemcen, 13000 Tlemcen /Algérie
}

*Corresponding Author: BEREKSI REGUG M, University Tlemcen, Algeria Email: meryem.bereksireguig@yahoo.fr

\begin{abstract}
The Mediterranean basin has significant natural resources including a proven diversity of flora. The Anacardiaceae family has around 800 tropical and subtropical species, with some representatives around the Mediterranean. Most of the plants of this family are non- toxic plant. They even have many properties. Our work consists to study the bio-insecticidal power of essential oils of Pistacia lentiscus and Pistacia atlantica of the Anacardiaceae family in the Tlemcen region by molecular modeling methods to inhibition of the enzyme $\alpha$-amylase which is a digestive enzyme of Dociostaurus maroccanus using phenolics compounds derived from essentiels oil of aromatic plants: Elemol; Spathulenol; Myrcene; Beta- myrcene; Terpinen-4-ol; Bornyl acetate. Elemol give the best docking score, its interactions with $\alpha$-amylase has the lowest energy score compared to the other complexes.
\end{abstract}

Keywords: Biopesticides, Pistacia lentiscus, Pistacia atlantica, molecular modeling methods

\section{Introduction}

The Mediterranean basin hotspot is one of the most remarkable regions on earth for its great biological (plant and animal) and landscape diversity, marked by a unique climate with cool, wet winters and hot, dry summers, which favours the establishment of various kind of vegetation. Vegetation consists chiefly of deciduous trees and perennial plants. The Anacardiaceae family is part of this vegetation, particularly in northern Algeria.

Anacardiaceae family's plants in clude trees, shrubs containing oleo-resineous secretory Channels. In fact, they exude oils, milky sap, resin or wax with various applications.

For centuries, herbal medicine has been recognized for its ease of use. The effectiveness and benefits of these plants on human and animal health make the man indisputable means on the preventive and curative plan. Use of these essential oils, form the basis of phytotherapy. In addition, it is considered today as an essential path towards new pharmaceutical avenues as an alternative to chemical products.

Dociostaurus maroccanus is one of the main locust pests of the order Orthoptera. Due to the favourable ecological conditions, these pests can be dangerous when they proliferate and cause damage to crops through their gregariousness (El Ghadraoui et al., 2003). The economic and ecological impact of locusts on crops and pastures has long been recognized. For such needs, the focus is rather on the biological control of these species.

Then, for this purpose, with the development of computer tools, molecular modeling and and specifically molecular docking (molecular assembly or docking) has quickly taken over biological research field. Molecular docking's main objective is to predict the most favourable conformation (position and relative orientation) of the ligand within its receptor. 
The "Pistacia lentiscus" is a shrub belonging to the branched (ramified) Anacardiaceae family, three meters high, with a strongly pungent resin smell. It is widespread in the Mediterranean basin, growning in the wild in scrub (maquis) and garrigues in all types of soils, although it prefers siliceous grounds. In Algeria, mastic tree is found along the tell and forest areas. (More and White, 2005). It prefers nutrient-poor soils, low water and also in long exposure to high temperatures and solar radiationThe Atlas pistachio or (Pistacia atlantica). It is a mighty tree that can reach 20 $\mathrm{m}$ in height, with a well-individualized trunk and deciduous. This forest species, known as freeriding, accommodates allsoils except sand. It is satisfied with a low rainfall of around $150 \mathrm{~mm}$ and sometimes less (Benhssaini and Belkhodja, 2004).

The present work is related to comparing the bio-insecticide power of two aromatic plants which are Pistacia lentiscus and Pistacia atlantica to control the locust pests, Dociostaurus maroccanus Thumberg, 1815.
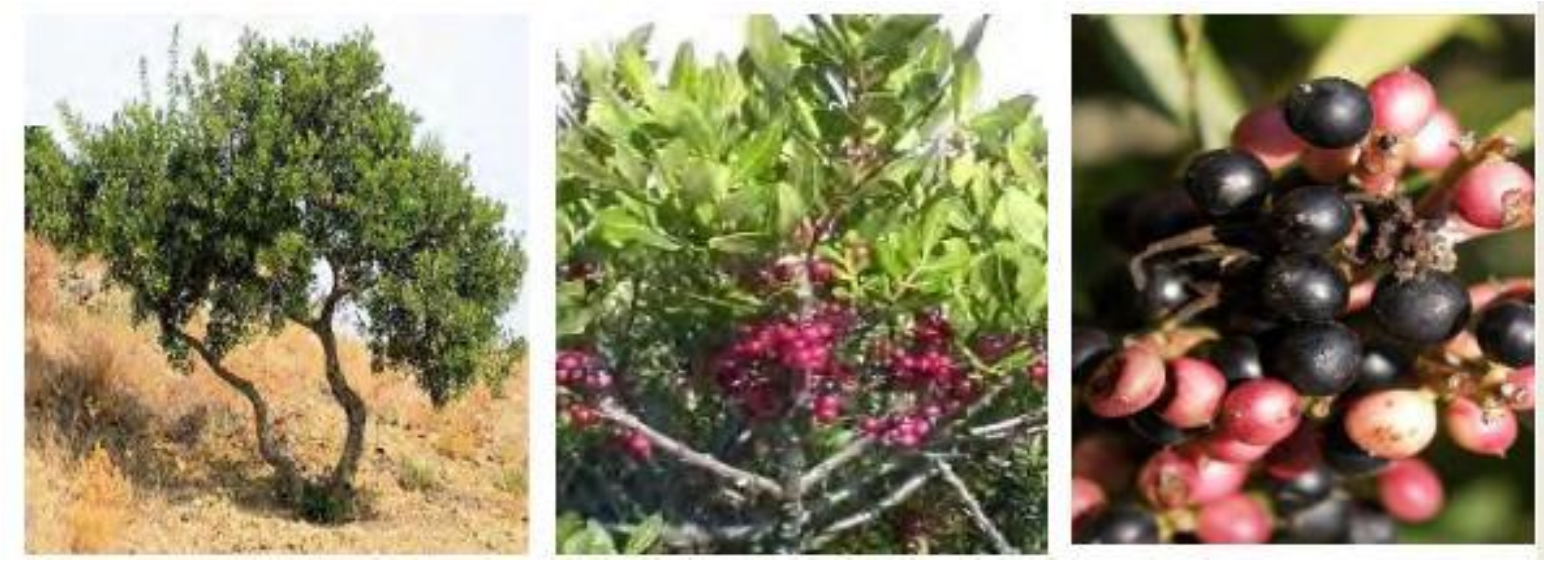

Figure 1. Representation of tree leaves and fruit of Pistacia lentiscus (Dahmani 2015)

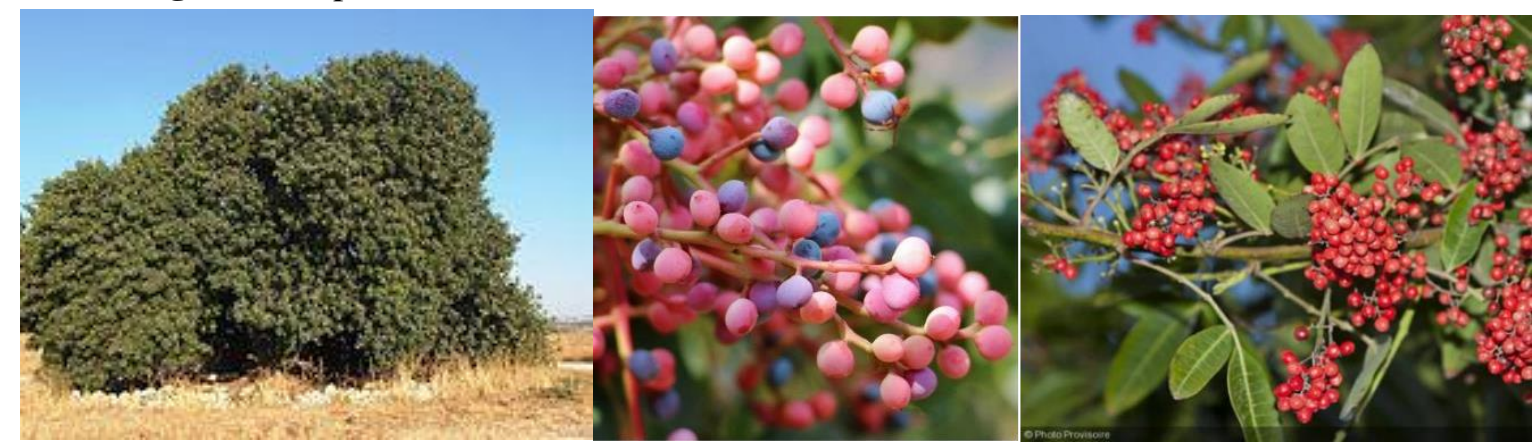

Figure 2. Representation of tree leaves and fruit of Pistacia atlantica (Nafil 2017)

\section{Material and methods}

\section{Enzyme and inhibitors preparation}

The ligands used were chosen based on the most important efficiency in each part of the plant (leaf and fruit) (Table1) The chemical structure of these ligands was obtained from the database "Pubchem" (Table 2), and drew up the ligands from the software "Chemdraw" version 12.0.2.1076, then saved them in "Mol» format, the reafter optimized the ligands with "Hypercham" software version 8.0.10 and saved them in "Mol » format for molecular docking with the Molecular Operating Environment «MOE » software. Table 3 represents the molecular weights of ligands was obtained from the database "Pubchem". 
Bereksi Reguig et al, 2021. Genet. Biodiv. J, Special issue (Characterization and valorisation of Plants), 39-48

Table 1. Molecules present in the essential oils of the plants

\begin{tabular}{|c|c|c|}
\hline \multirow[t]{2}{*}{ Plant species } & \multicolumn{2}{|c|}{ Essential oil (\%) } \\
\hline & leafs & fruits \\
\hline Pistacia lentiscus & $\begin{array}{l}\text { - } \alpha \text {-pinene } 11 \\
\text { - limonene } 10.3 \\
\text { - Myrcene } 39.2 \\
\text { - Terpinen.4.ol } 29.9 \\
\text { - } \alpha \text {-terpineol } 15\end{array}$ & $\begin{array}{l}-\alpha \text {-pinene } 22 \\
-\beta \text { - myrcene } 54\end{array}$ \\
\hline Pistacia atlantica & $\begin{array}{l}\text { - } \alpha \text {-pinene } 10.9 \\
\text { - delta-3-carene } 56 \\
\text { - Spathulenol } 22 \\
\text {-terpinen-4-ol } 16 \\
\text { - beta-pinene } 13 \\
\text {-Elemol } 20\end{array}$ & $\begin{array}{l}\text { - Bornyl-acetate } 21.5 \\
\text { - Myrcene } 34 \\
\text { - Sabinene } 19.5\end{array}$ \\
\hline
\end{tabular}

Table2. 2 D\&3D representations of the all ligands used in the experiment. The ligands structures were taken from PubChem server (www.pubchem.ncbi.nlm.nih.gov).

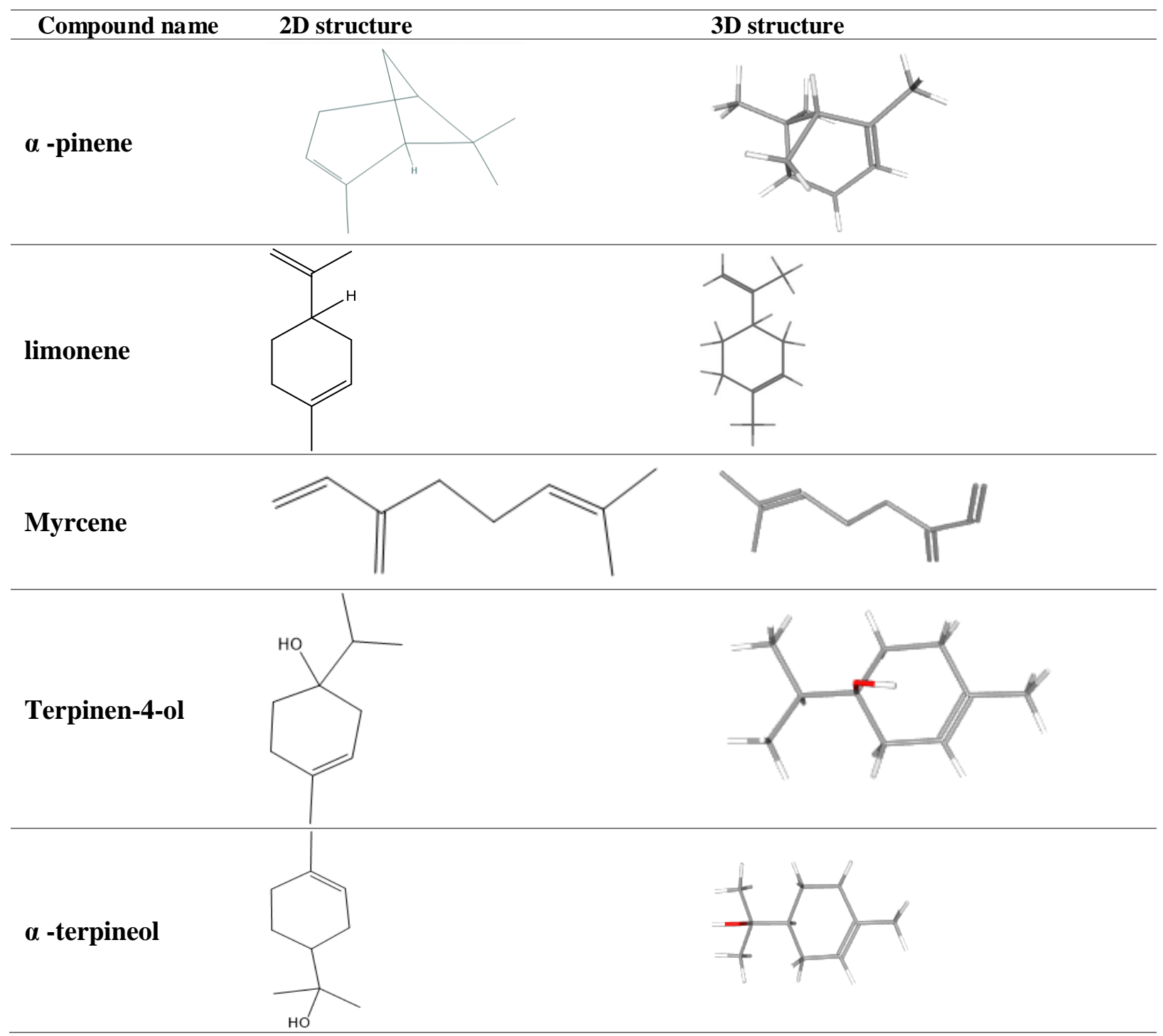


$\beta$ - myrcene
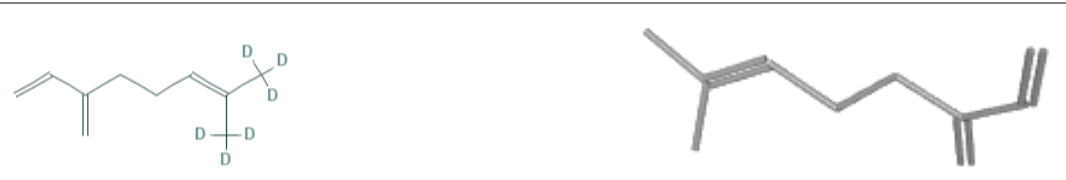

Delta-3-carene
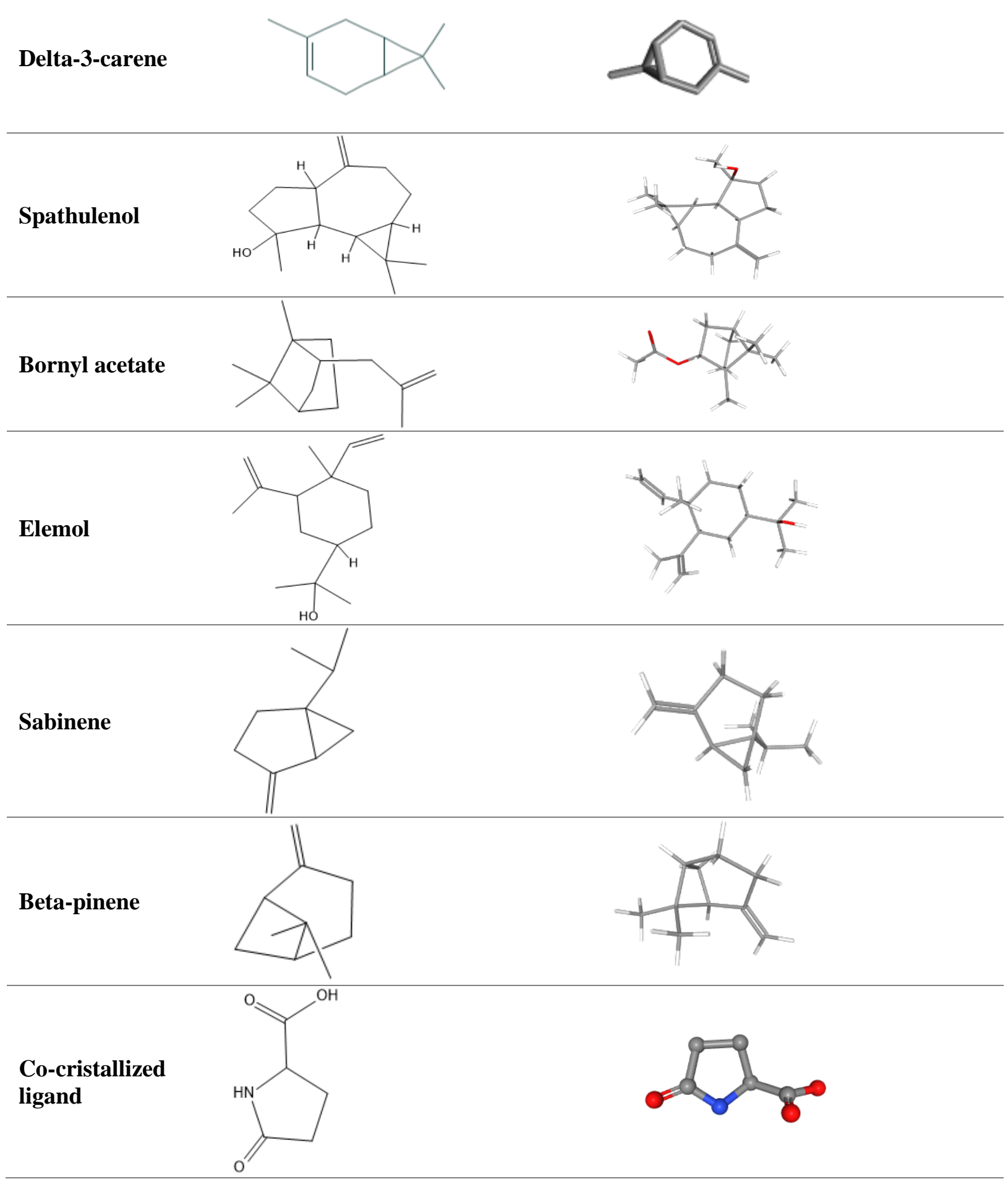
Table 3. Properties of tested molecules

\begin{tabular}{|c|c|c|}
\hline Ligands & Weight $(\mathrm{g} / \mathrm{mo})$ & TPSA $\left(\AA^{2}\right)$ \\
\hline$\alpha$-pinene & 136,23 & 0(0: don, $0:$ acc $)$ \\
\hline limonene & 136,23 & 0(0: don, $0:$ acc $)$ \\
\hline Myrcene & 136,23 & 0(0: don, $0:$ acc $)$ \\
\hline Terpinen.4.ol & 154,25 & 20,2(1: don, 1: acc) \\
\hline$\alpha$-terpineol & 154,25 & 20,2(1: don, 1: acc) \\
\hline$\beta$ - myrcene & 136,23 & $0(0:$ don, $0:$ acc $)$ \\
\hline Delta-3-carene & 136,23 & 0 (0: don, $0:$ acc $)$ \\
\hline spathulenol & 220,35 & 20,2(1: don, 1: acc) \\
\hline Terpinolène & 136,23 & 0 (0: don, 0: acc) \\
\hline Bornyl acetate & 196,29 & 26,3(0: don, 2: acc) \\
\hline Elemol & 22,37 & 20,2(1: don, 1: acc) \\
\hline sabinene & 136,23 & $0(0:$ don, $0:$ acc $)$ \\
\hline Beta-pinene & 136,23 & $0(0:$ don, $0:$ acc $)$ \\
\hline
\end{tabular}

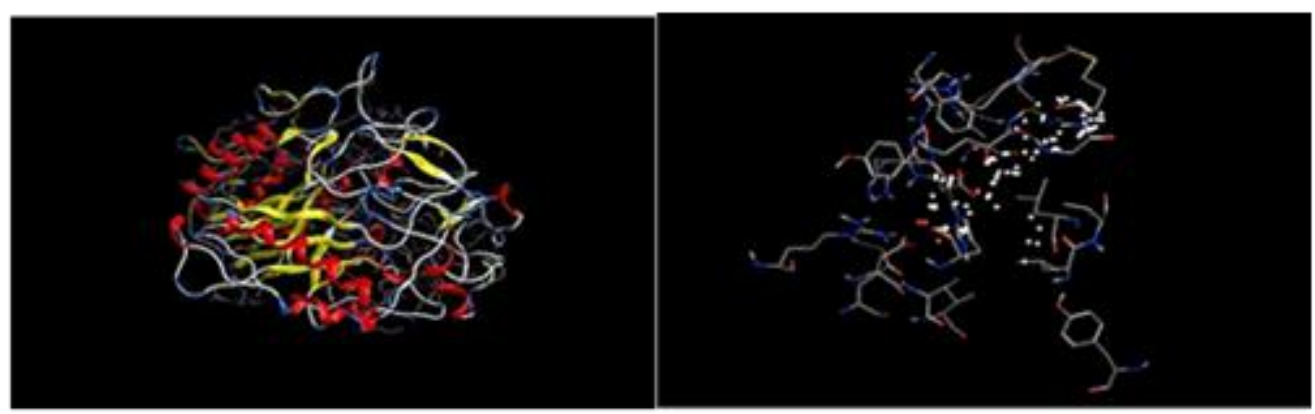

Figure 3. 3D structure of alpha-amylase enzyme. The structure was taken from Protein Data Bank online server (https://www.rcsb.org/) and Molecular Operating Environment (MOE).

The table 4 represents the chemical properties of enzyme downloaded from Protein Data Bank online server.

Table 4. Properties of the $\alpha$-amylase enzyme

\begin{tabular}{clllll}
\hline Protein & Classification & Method & Resolution & Number of chains & Chain length \\
\hline 1CLV & HYDROLASE & $\begin{array}{l}\text { X-Ray } \\
\text { diffraction }\end{array}$ & $\mathbf{2 A}^{\circ}$ & two chains & $\mathbf{5 0 3}$ \\
\hline
\end{tabular}

\section{Molecular docking protocol}

Molecular docking calculations have been performed using the default standard MOE software parameters (Molecular operating environment, 2013). A docking simulation essentially consists of two stages: the docking itself and the scoring.

- Docking is the selection stage, which consists of placing the ligand in the active site of the protein and sampling the possible conformations, positions and orientations (poses), retaining only those that represent the most favorable modes of interactions.

- Scoring is the ranking stage, which consists in evaluating the affinity between the ligand and the protein and giving a score to the poses obtained during the docking phase. This score will enable the best pose among all those proposed to be selected.

\section{Molecular dynamics simulation}

The molecular dynamics simulation study was carried out for the ligand that was declared as the best among the selected molecules. From the analysis of the results, it was concluded that was the best ligand among the selected ligands and molecules. The molecular dynamics simulations study of 
Elemol and 1CLV docked complex was performed by iMODS. It is a fast, user-friendly and effective molecular dynamics simulation tool that can be used efficiently to investigate the structural dynamics of the protein complexes. It provides the values of deformability, B-factor (mobility profiles), eigenvalues, variance, co-varience map and elastic network. For a complex or protein, the deformability depends on the ability to deform at each of its amino acid residues. The eigenvalue has relation with the energy that is required to deform the given structure and the lower the eigenvalue, the easier the deformability of the complex.

Moreover, the eigenvalue also represents the motion stiffness of the protein complex. IMODS is a fast and easy server for determining and measuring the protein flexibility (Lopez -Blanco et al., 2011, Lopez- Blanco et al., 2014; Prabhakar et al., 2016; Awan et al., 2017)

\section{Results and discussions}

\section{Molecular docking simulation}

In order to find the residues that form the largest active site of amino-acids on the enzyme to get an intercation with ligands, "Finder site" module on the "MOE" software was used. The enzyme 1CLV contains 20 enzymatic cavities whose largest active site is made up of 21 amino acids that are: LEU 49- TRP 56- TRP 57- TYR 60- GLN 61-HIS 99-GLY 102- MET 103- LEU 150- VAL 151-LEU 153- ARG 183-ASP 185- ALA186-GLU 222-ILE 224-HIS 286- ASP 287-ARG 290 ASN 331ASP332. After the enzyme and ligands preparation, the next stage is the positioning of these inhibitors in the active site of the 1CLV enzyme. This requires the docking module using the "MOE" software. Once the ligand-receptor complex is formed (Figure 4), it will adapt the most stable conformation, namely with the lowest energy level. Once the complex was formed and analyze the results were obtained.

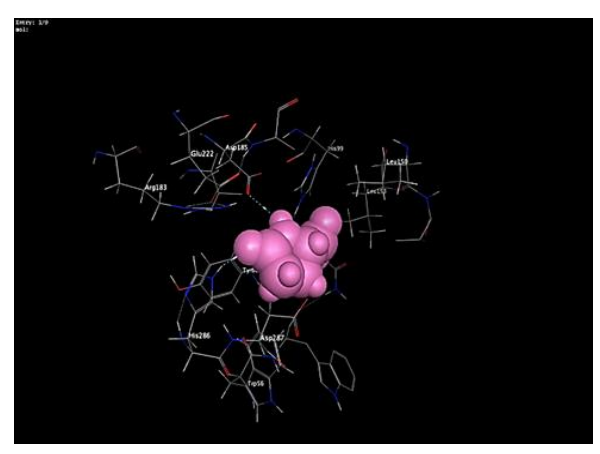

A

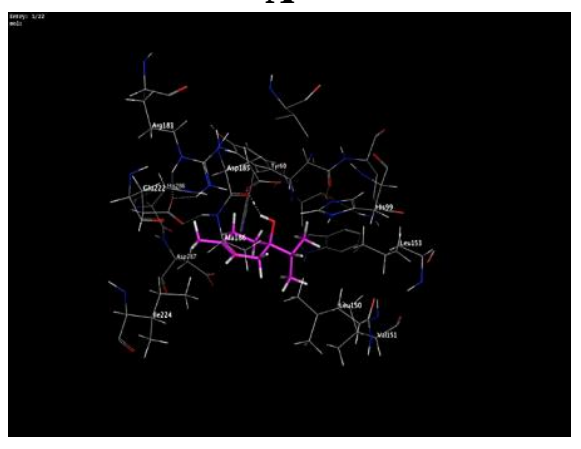

C

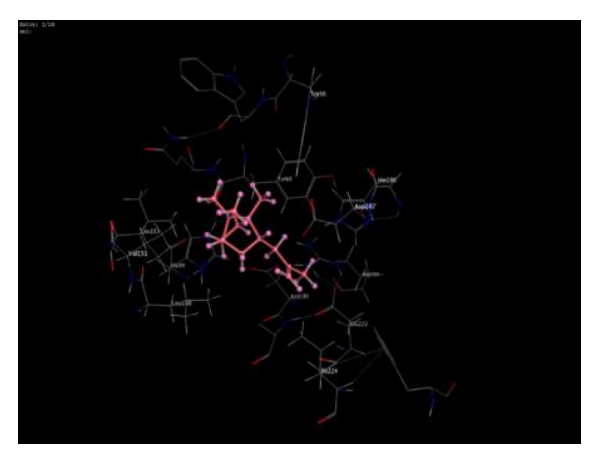

B

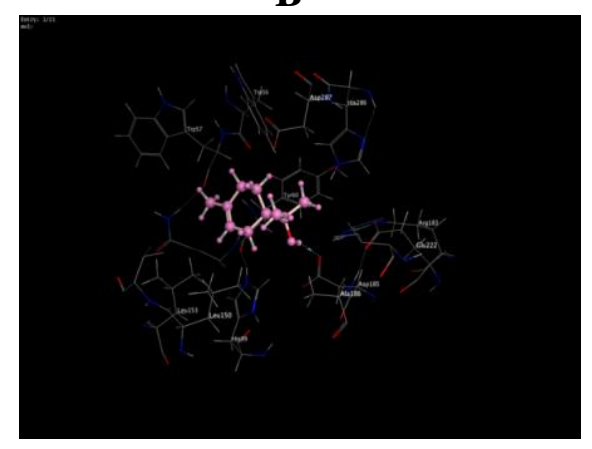

D

Figure 4. $3 \mathrm{D}$ representations of the best pose interactions between the ligands and their receptor. A. interaction between co-cristallization ligand and 1CLV, B. interaction between Spathulenol and $1 \mathrm{CLV}, \mathrm{C}$. interaction between terpinèn-4-ol and 1CLV, D. interaction between $\alpha$ - terpineol and 1CLV. 
The $3 \mathrm{D}$ representations of the best pose interactions between the ligands and their respective receptors were visualized using Molecular Operating Environment (MOE).

In order to compare the stability of the ligands reviewed in the active site of the 1CLV enzyme, molecular docking between the enzyme and the ligands was conducted (Table 5).

The highest score obtained after docking is that of Elemol with a score of $-4.9763 \mathrm{kcal} / \mathrm{mol}$, followed by Spathulenol with a score of $-4.9324 \mathrm{kcal} / \mathrm{mol}$ and one hydrogen interaction with ASP-185 of OD1 target active site, myrcene with a score of $4.7707 \mathrm{kcal} / \mathrm{mol}$, the score of the co-cristalized ligand is 3, $5513 \mathrm{kcal} / \mathrm{mol}, 5$ interactions ASP185, HIS286, HIS99, HIS99, HIS99.

The complex formed by Elemol-1CLV has the lowest values energy and giving the best docking score compared to co-cristalized ligand. According to these docking results can classify, Elemol as the good inhibitor of the enzyme 1CLV compared to the all ligands studied.

\section{Enzyme-ligand interaction}

Interactions between 2.5 and 3.1 are considered strong and interactions between 3.1 and 3.55 are assumed to be average. Interactions above 3.55 are weak or absent (Marianna et al., 2006).We have shown the interactions between the ligands and the enzyme (Figure 5).

The distances measured between the ligands and the amino-acids of the active site vary between $2.99^{\circ}$ and $3.27^{\circ}$. The average interactions between Elemol and the active site of the enzyme amylase with a distance of 3,03 and $3.27 \mathrm{~A}^{\circ}$, this interaction is considered average because it is between $3.1 \AA$ and $3.55 \AA$, this interaction is between OD1 and the amino acid ASP185 and NE2 and the amino acid HIS 286 present in the enzymatic cavity of our enzyme with an energy of -1.6 and 2,1 $\mathrm{kcal} / \mathrm{mol}$.

Table 5. Docking results (binding energy) of all ligands and the control along their respective number of hydrogen bonds as well as interacting amino-acids.

\begin{tabular}{|c|c|c|c|c|c|}
\hline ligands & score & $\begin{array}{l}\text { Interaction with } \\
\text { residues }\end{array}$ & Interaction type & $\begin{array}{l}\text { Distance } \\
\left(A^{\circ}\right)\end{array}$ & Energy \\
\hline \multirow{2}{*}{ Elemol } & - & OD1- ASP185 & $\mathrm{H}$ - donneur & 3,03 & - \\
\hline & 4.9763 & NE2 - HIS286 & $\mathrm{H}$ - accepteur & 3.27 & 2.1 \\
\hline spathulenol & - & OD1- ASP185 & H-donneur & 3,15 & - \\
\hline myrcène & - & / & I & 1 & 1 \\
\hline$\beta$-Myrcène & - & I & I & I & I \\
\hline Terpinen-4- & - & OD1- ASP185 & $\mathrm{H}$ - donneur & 3,26 & - \\
\hline Bornyl & - & 1 & 1 & 1 & I \\
\hline a-terpinéol & - & OD1 - ASP 185 & H- donneur & 2,99 & - \\
\hline Terpinolene & - & 1 & 1 & 1 & I \\
\hline limonene & $-4,42$ & 1 & 1 & 1 & 1 \\
\hline Sabinene & - & I & 1 & 1 & I \\
\hline$\beta$-pinene & - & l & l & l & I \\
\hline Delta-3- & $\begin{array}{l}1 \\
-\end{array}$ & l & l & l & I \\
\hline$\alpha$-pinene & 3,8957 & l & l & I & I \\
\hline References & - & OD1 - ASP185 & H-donor & 3,41 & - \\
\hline \multirow[t]{5}{*}{ ligands } & 3,5513 & NE2 - HIS286 & H- & & 0,7 \\
\hline & & ND1 - HIS99 & acceptor & 3,04 & - \\
\hline & & NE2 - HIS99 & ionic & & $\mathbf{4 , 4}$ \\
\hline & & NE2 - HIS99 & ionic & 3,87 & \\
\hline & & & ionic & 3,23 & - \\
\hline
\end{tabular}



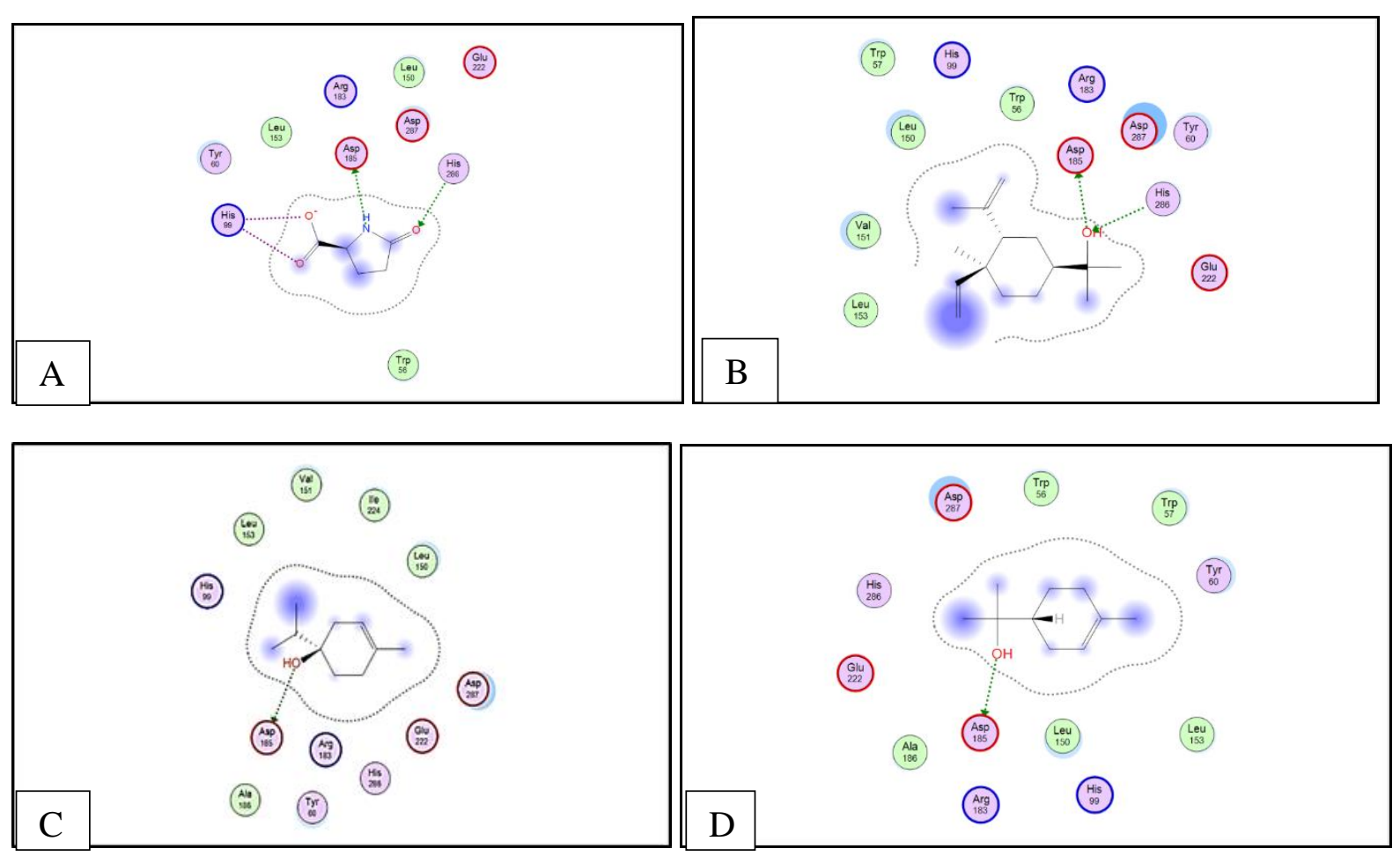

Figure 5. 2D representations of the best pose interactions between the ligands and their receptor.

A. interaction between co-cristallized ligand and $1 C L V, B$. Interaction between Elemol and $1 C L V$, C. interaction between terpinèn-4-ol and 1CLV, D. interaction between alpha-terpineol and 1CLV.

\section{Molecular dynamics simulation}

The normal mode analysis (NMA) of Elemol - 1CLV complex is illustrated in Figure 6a. The deformability graph of the complex illustrates the peak in the graphs correspond to the regions in the protein with deformability (Figure. 6b) The B factor graph of the complex gives easy visualization and understanding of the comparison between the NMA and the PDB field of the complex (Figure. 6c). The eigenvalue of the complex is illustrated in Figure 6d. The docked complex generated eigenvalue of $3.500969 \mathrm{e}-04$. The variance graph indicates the individual variance by red colored bars and cumulative variance by green colored bars Figure 6. Figure. 6f illustrates the covariance map of the complexes where the correlated motion between a pair of residues is indicated by red color, uncorrelated motion is indicated by white color and anti- correlated motion is indicated by blue color. The elastic map of the complex shows the connection between the atoms and darker gray regions indicate stiffer regions Figure. $6 \mathrm{~g}$.

From the molecular dynamics study of Elemol- 1CLV docked complex, it is clear that the complex had a very good amount of deformability as well as it had low eigenvalue of $3.500969 \mathrm{e}-04$, for this reason, this lower eigenvalue, represent the easier the deformability of the complex (Figure 6b. Figure $6 \mathrm{~d}$ and also represents the motion stiffness of the protein complex. However, the variance map showed high degree of cumulative variances than individual variances (Figure .6e). The covariance and elastic network map also produced satisfactory results (Figure $6 \mathrm{f}$ and $6 \mathrm{~g}$ ). 


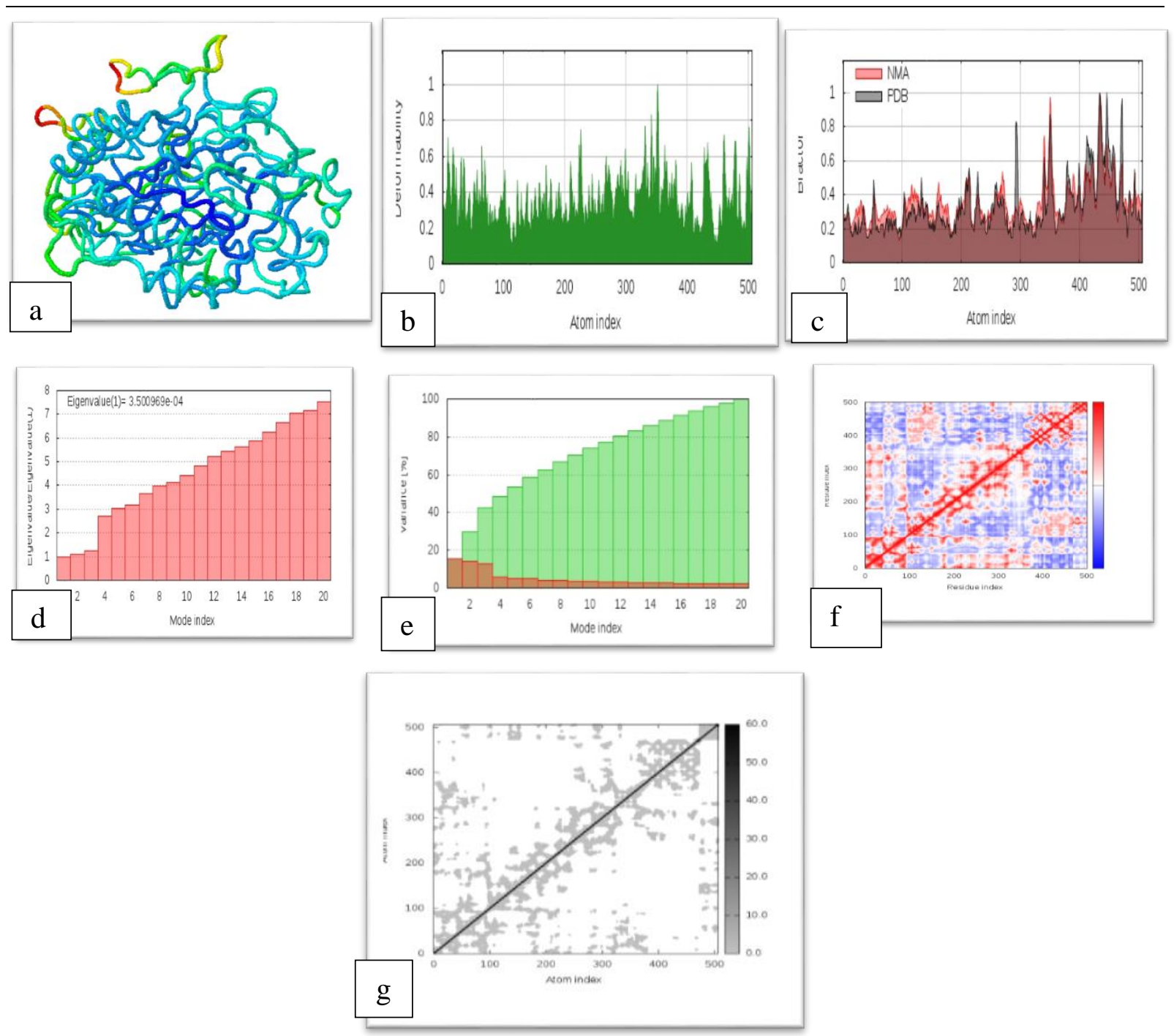

Figure. 6. Results of molecular dynamics simulation of Hexadecanoic acid-1CLV.

(a) NMA mobility, (b) deformability, (c) B-factor, (d) eigenvalues, (e) variance (red color indicates individual variances and green color indicates cumulative variances), $(f)$ co-variance map (correlated (red), uncorrelated (white) or anti-correlated (blue) motions) and $(\mathrm{g})$ elastic network (darker gray regions indicate more stiffer regions) of the complex.

In North Africa, the problem of harmful insects including locusts has always been and remains one of the major concerns of farmers. Cricket damage poses a threat to the stability of agricultural areas. The damage and havoc attributed to these insects is as much a result of larval activity as that of adults (Acheuk, 2012). To control these pests in the area the use of insecticides is of very frequent use and continues to increase from year to year, which most often causes adverse effects on humans and the environment. The use of cleaner control methods has become a necessity.

According to Bouchenada (2007); the oily extracts of the fruit of Melia azedarach has insecticidal effects on the larvae and adults of Ocneridia volxemi. Bouchareb, (2016) mentioned that, Pistacia lentiscus has significant insecticidal potential against the Taxoptera aurantii aphid. According to Hamdan and Afifi. (2004), the pharmaceutical properties of pistacia atlantica include a hypoglycemic activity that is probably related to the inhibitory activity of $\alpha$-amylase which confirms our work.

According to the obtained results from molecular docking, thirteen « enzyme-ligand complexes are formed. It has been found that there are several ligands that promote the inhibition of the 
enzyme 1CLV through their weakest scores. Compared to the score of the co-crystallization inhibitor $(-3,5513 \mathrm{kcal} / \mathbf{~ m o l})$.

According to the obtained scores, the ligands Elemol; Spathulenol ; Myrcene ; Beta- myrcene; Terpinen-4-ol ; Bornyl acetate, they have a bio-insecticidal power towards the $\alpha$ - amylase enzyme of the digestive system of Dosciostaurus marrocanus.

Regarding the review and according to the results obtained; the Elemol obtained from the extraction of leaves of Pistacia atlantica; are the best inhibitor of the alpha-amylase enzyme when compared with the components of Pistacia lentiscus.

\section{Conclusion}

In the present work, we are interested in the molecular interactions between the $\alpha$-amylase enzyme of the digestive system of Dosciostaurus marrocanus; we theoretically test the help of the molecular modeling, more precisely the molecular docking of the "MOE" software and Molecular Dynamics simulation ;the inhibitory potency of ligands resulting from the extraction of essential oils from the "leaves and fruit" part of the following plants: Pistacia lentiscus and Pistacia atlantica that belong to the Aanacardiaceae family. Based on the results, can be concluded that Elemol of the species Pistacia atlantica has an inhibitory potency of the $\alpha$-amylase enzyme to control Dosciostaurus marrocanus.

\section{References}

Amhamdi H. Aouintil F. Wathelet JP. Elbachiri A 2009. Chemical Composition of the Essential Oil of Pistacia lentiscus Rec. Nat. L. from Eastern Morocco. Production (2): 90-95.

Bouchenada M 2007. Recherches sur les Orthoptères. Etude bioécologique et essais de lutte biologique sur Ocneridia volxemi Bol. (Orthoptera, Pamphagidae) dans la région de Sétif.thèse de doctorat en Biologie animale. Université FERHAT ABBAS SETIF.

Benhassaini H. Belkhoudja M 2004 - Le pistachier de l'Atlas en Algérie: entre survie et disparition. La feuille et l'aiguille, $\mathrm{N}^{\circ}$ 54, pp 1-2.

Dahmani 2015. Etude édapho-floristique du Pistacia lentiscus des zones littorals et continentals de l'ouest Algérien. Memoire Master. Ecologie végétale. Université Abou bekr Blkaid Tlemcen.

Hamdan, II. Afifi FU 2004. Studies on the in vitro and in vivo hypoglycemic activities of some medicinal plants used in treatment of diabetes in Jordanian traditional medicine. Journal of Ethnopharmacology, 93, 117121. http://dx.doi.org/10.1016/j.jep.2004.03.033.

EL. GHADRAOUI1 L. PETIT D. EL YAMANI J 2003. Le site Al- Azaghar (Moyen-Atlas, Maroc) : un foyer grégarigène du criquet marocain Dociostaurus maroccanus (Thunb., 1815). Université Sidi Mohammed Ben Abdellah, Faculté des Sciences et Techniques, Département de Biologie, Bulletin de l'Institut Scientifique, Rabat, section Sciences de la Vie, 2003, n²5, 81-86.

Lopez-Blanco JR. Aliaga JI. Quintana-Ort S. Chacon P 2014. iMODS: Internal coordinate's normal mode analysis server. NucleicAcids Research, 42(W1), W271-276. doi:10.1093/nar/gku339

Lopez-Blanco JR. Garzon JI. Chacon P 2011. iMod: Multipurpose normal mode analysis in internal coordinates. Bioinformatics, 27(20), 2843-2850. doi:10.1093/bioinformatics/btr497.

More D. White J 2005. Encyclopédie des Arbres :Plus de 1800 Espèces et Variétés du Monde, (Ed.), Flammarion : 18-24.

Nafil D 2017. Position systématique de Pistacia atlantica Desf dans la region de Tlemcen. Memoire master. Ecologie végétale .Univ Abou bekr Belkaid Tlemcen. 